CLINICAL HEMORHEOLOGY, Vo1. 3, pp. 217-218, 1981

0271-5198/81/030217-02\$02.00/0 Printed in the USA.

Copyright (c) 1981 Pergamon Press Ltd. All rights reserved.

\title{
EDITORIAL
}

\section{CONCERNING CERTAIN CONTRIBUTIONS IN THIS ISSUE}

Both the IVth International Congress of Biorheology held in Tokyo from 27. July to 1. August 1981 at Jikei University School of Medicine and the Satellite Meeting "International Symposium on Hemorheological Approach to Cardiovascular Diseases" at the National Cardiovascular Center Research Institute, Suita, Osaka, Japan were scientifically highly successful.

The abstracts of communications presented at the Congress in Tokyo have been published in BIORHEOLOGY volume 18, issues 1 and 2 , 1981. We thought it of interest to our Readers to publish abstracts of Papers on clinical hemorheology also in this issue in order to inform them about these presentations, which deal either with clinical hemorheology or with hemorheological findings of interest to the practice of medicine and surgery. However, we are not including abstracts of Papers on theoretical and experimental hemorheology, because they are not of rather immediate concern to the practice of medicine.

Al1 Papers presented at the Satellite Meeting in Osaka will be published this year as Supplement 1 to CLINICAL HEMORHEOLOGY. Since supplements to CLINICAL HEMORHEOLOGY cannot be provided as part of the subscription to our Journal, such supplements will have to be purchased separately from Pergamon Press.

This issue contains also the abstracts of the Plenary Lectures, because, we believe, they will be appreciated by our Readers.

It should be noted that the Plenary Lectures will be published in the first issue of volume 19, 1982 of BIORHEOLOGY. BIORHEOLOGY will also publish the symposia papers of the Tokyo Congress. However, the Congress Symposium, entitled "Recent Advances in Clinical 
Hemorheology", will appear in a forthcoming issue of CLINICAL HEMORHEOLOGY and not be included in BIORHEOLOGY. The present issue No. 3 contains a list of topics of all five Congress Symposia, as well as the program of the ceremony of the Poiseuille Award, bestowed on Alex Silberberg (Israel).

As far as Papers on clinical hemorheology presented at the Congress in Tokyo are concerned, their authors can submit these communications for publication to any of the Editors of CLINICAL HEMORHEOLOGY.

Furthermore, this issue contains a contribution entitled "Hemorheology in Japan. A Brief History" by A.L. Copley, originally invited as a message for the book "Present Status of Cardiovascular Hemorheology in Japan". This book was issued for the participants of the Congress in Tokyo and the Satellite Meeting in Osaka. It contains arother contribution of interest to our Readers and is therefore included in this issue. It is the article by Masao Ikeda, entitled "Cardiovascular Diseases in Japan".

A 1ist of topics of the Invited Lectures and Papers of the scientific program at the Osaka Symposium meeting is included in this issue. However, the abstracts of the Satellite Meeting in osaka are not included, because they will appear together with the articles in Supplement Number 1 of CLINICAL HEMORHEOLOGY.

We should like to point out that, beginning with this issue, we provide our Readers with abstracts selected by the Editor of our Abstract Section, Klaus-U. Benner. In future issues we shall continue publishing in the Abstract Section abstracts selected by him for our Journal. The abstracts in the Abstract Section will not include those of Congresses of the International Society of Biorheology or of meetings pertaining to clinical hemorheology, associated with or sponsored by our Society. Such abstracts, however, will be published separately under appropriate headings in CLINICAL HEMORHEOLOGY.

\author{
Alfred L. Copley Siegfried Witte
}

Editors-in-Chief 